\title{
RLIP76, a non-ABC transporter, and drug resistance in epilepsy Sanjay Awasthi ${ }^{1}$, Kerri L Hallene ${ }^{2}$, Vince Fazio ${ }^{2}$, Sharad S Singhal ${ }^{1}$, Luca Cucullo², Yogesh C Awasthi ${ }^{4}$, Gabriele Dini ${ }^{2}$ and Damir Janigro*2,3
} \begin{abstract}
TX USA
Email: Sanjay Awasthi - sawasthi@uta.edu; Kerri L Hallene - hallenk@ccf.org; Vince Fazio - faziov1@ccf.org;

Sharad S Singhal - ssinghal@uta.edu; Luca Cucullo - cuculll@ccf.org; Yogesh C Awasthi - ycawasth@utmb.edu; Gabriele Dini - gabriele.dini@email.it; Damir Janigro* - janigrd@ccf.org

* Corresponding author
\end{abstract}

Address: ${ }^{1}$ Department of Chemistry and Biochemistry, University of Texas at Arlington, Arlington, TX USA, ${ }^{2}$ Cerebrovascular Research, Department of Neurological Surgery, Cleveland Clinic Foundation, Cleveland, OH USA, ${ }^{3}$ Molecular Medicine, Cleveland Clinic Lerner College of Medicine, Cleveland, OH USA and ${ }^{4}$ Department of Human Biological Chemistry and Genetics, University of Texas Medical Branch at Galveston, Galveston,

Published: 27 September 2005

BMC Neuroscience 2005, 6:61 doi:|0.1|86/|47|-2202-6-6I

This article is available from: http://www.biomedcentral.com/|47|-2202/6/6I

This is an Open Access article distributed under the terms of the Creative Commons Attribution License (http://creativecommons.org/licenses/by/2.0), which permits unrestricted use, distribution, and reproduction in any medium, provided the original work is properly cited.

\begin{abstract}
Background: Permeability of the blood-brain barrier is one of the factors determining the bioavailability of therapeutic drugs and resistance to chemically different antiepileptic drugs is a consequence of decreased intracerebral accumulation. The ABC transporters, particularly Pglycoprotein, are known to play a role in antiepileptic drug extrusion, but are not by themselves sufficient to fully explain the phenomenon of drug-resistant epilepsy. Proteomic analyses of membrane protein differentially expressed in epileptic foci brain tissue revealed the frequently increased expression of RLIP76/RALBPI, a recently described non-ABC multi-specific transporter. Because of a significant overlap in substrates between P-glycoprotein and RLIP76, present studies were carried out to determine the potential role of RLIP76 in AED transport in the brain.
\end{abstract}

Results: RLIP76 was expressed in brain tissue, preferentially in the lumenal surface of endothelial cell membranes. The expression was most prominent in blood brain barrier tissue from excised epileptic foci. Saturable, energy-dependent, anti-gradient transport of both phenytoin and carbamazepine were demonstrated using recombinant RLIP76 reconstituted into artificial membrane liposomes. Immunotitration studies of transport activity in crude membrane vesicles prepared from whole-brain tissue endothelium showed that RLIP76 represented the dominant transport mechanism for both drugs. RLIP76-/ knockout mice exhibited dramatic toxicity upon phenytoin administration due to decreased drug extrusion mechanisms at the blood-brain barrier.

Conclusion: We conclude that RLIP76 is the predominant transporter of AED in the blood brain barrier, and that it may be a transporter involved in mechanisms of drug-resistant epilepsy.

\section{Background}

Each year approximately 160,000 persons are diagnosed with epilepsy, and about 10,000 of these individual develop drug-resistant epilepsy [1]. The causes of drugresistant epilepsy are numerous, many due to ontogenic abnormalities in brain maturation, severe brain injuries with resultant irreversible changes to cerebral neuroglial organization and inhibitory neuron function, kindling phenomenon, seizure-induced disturbances of oxygen supply, as well as acquired (or hereditary) changes in 
transporter proteins of the blood-brain barrier which function in the efflux of anti-epileptic drugs (AEDs) from the brain. The latter mechanisms have been the focus of intense efforts to develop new rationally designed AEDs that could bypass these transport mechanisms. Unfortunately, the identity of the multiple transport mechanisms of the blood brain barrier, and the individual role of each in mediating drug-resistant epilepsy is as yet incompletely defined.

The ABC-family transporters have been the subject of considerable interest in the mechanisms of drug-resistant epilepsy [2,3]. The prototypical ABC transporter, Pglycoprotein (Pgp, MDR1, or mdr1 gene product), as well as MRP2, and BCRP are expressed in the blood-brain barrier [2]. Endothelial expression of Pgp has been demonstrated, and the role of Pgp in regulating brain drugconcentrations has been established in knockout mouse studies [4]. These studies evaluated the transport of a number of centrally acting drugs including antipsychotics, ant emetics, and natural product antineoplastic agents. The only AED examined, phenytoin (PHE), appeared to be a weak substrate of Pgp in intact cell transport experiments. Carbamazepine (CBZ) has been found not to inhibit Pgp mediated transport, thus would be a poor substrate [5]. Recently, studies examining the ability of AED to competitively inhibit the transport activity of Pgp have found little effect of AEDs on Pgp activity, and then only at concentrations well above clinically achieved therapeutic levels [6]. Although Pgp appears to mediate some minor transport activity towards most CNS active agent, the greatest CSF/plasma ratios (6.6-17 fold) were seen with antipsychotics and antiemetics rather than AEDs, evidence has been presented which suggests that there have been no reports directly demonstrating transport of any AED by Pgp in an isolated system [7].

In epileptic patients, expression of MDR1 has a complex pattern that does not directly support a significant pharmacokinetic role for MDR1 in human epilepsy since MDR1 expression was found in both blood-brain barrier and parenchymal cells in epileptic brain [8-10]. This is based on the possibility that expression of MDR1 in glia may actually favor drug interactions with neuronal by reducing the accumulation of drug in the glial syncitium. Conversely, parenchymal expression may shift concentrations in the extracellular and intracellular space or may mediate compartmentalization, and thus may reduce concentrations of antiepileptic drugs at their target sites. The fact that MDR1 may not be a crucial determinant for multiple drug resistance to antiepileptic drugs has been recently challenged in a number of reports [11-13]. Other ABC-transporters, most notably MRP2 and BCRP have also been localized to the blood-brain barrier, but similarly, direct evidence for the ability of these proteins to transport AEDs in isolated systems has been lacking. Because of the lack of information regarding the kinetic parameters of transport, the relative contributions of different $A B C$ transporters in mediating drug-resistant epilepsy remains unknown and a major impediment to development of novel targeted anti-epileptic agents.

We have recently described a novel non-ABC mutispecific transporter, RLIP76, a multifunctional modular protein found ubiquitously from Drosophila to humans [14-17]. It is encoded in humans on chromosome $18 \mathrm{p} 11.3$ by a gene with 11 exons and 9 introns. RLIP76 is a $76 \mathrm{kDa}$ protein product of this gene, but splice-variants including a $67 \mathrm{kDa}$ peptide and longer 80 or $102 \mathrm{kDa}$ peptide, cytocentrin have been identified [18]. RLIP7 6 was cloned as a Ral-binding protein and predicted to be an effector involved in regulation of membrane plasticity, movement, and endocytosis [17,19-21]. RLIP7 6 was identified as a highly active efflux mechanisms for removing glutathione-electrophile conjugate (GS-E, i.e. LTC4) from cells [22]. In addition to GS-E, the exceptionally broad substrate specificity of RLIP76 extends to Pgp substrates including anthracycline and vinca alkaloids, towards which it mediates resistance [23-27]. Studies on proteomic screening of epileptic foci led to the identification of RLIP76 as being frequently up-regulated. Present studies were carried out to examine the role of RLIP76 in AED transport in the blood-brain barrier.

\section{Results and discussion}

RLIP7 6 was expressed in all normal human tissues examined, more prominently in breast, heart, liver and erythrocytes, and less so in colon and brain parenchyma (Fig. 1a, b \&1c). Significant expression was seen in malignant human cell lines including the PC-3 human prostate cancer and H1299 human non-small cell lung cancer cell lines. Whereas RLIP76 was barely detectable in normal brain parenchyma or vessels, blood vessels from epileptic patients has a markedly increased expression of RLIP7 6 (Fig. 1b \&1c).

Epileptic brain sections obtained from multiple drug resistant patients also revealed substantial differences compared to non-epileptic brain. By immunocytochemical analysis, we discovered widespread RLIP76 expression in the cerebral vasculature from epileptic brain. We used double label immunofluorescence to reveal that RLIP76 co-localized with the multidrug resistance transporter Pglycoprotein (MDR1) but not with NeuN or GFAP (Fig. $1 \mathrm{~d}, \mathrm{e}, \mathrm{f}$, and $1 \mathrm{~h})$. However, while MDR1 was expressed in both parenchymal and endothelial cells [8,9], RLIP76 immunoreactivity was limited to the vasculature. No overlapping expression of RLIP76 was observed in GFAP positive astroglia (Fig. 1e) or NeuN positive neurons (Fig. 1d). By confocal analysis, RLIP7 6 expression was found in 

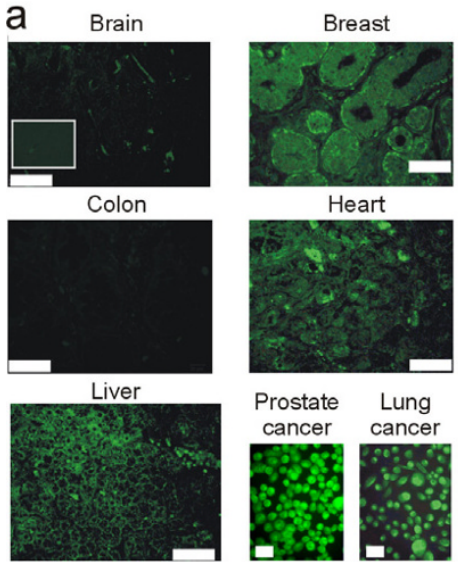

Heart
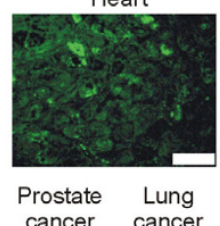

cance
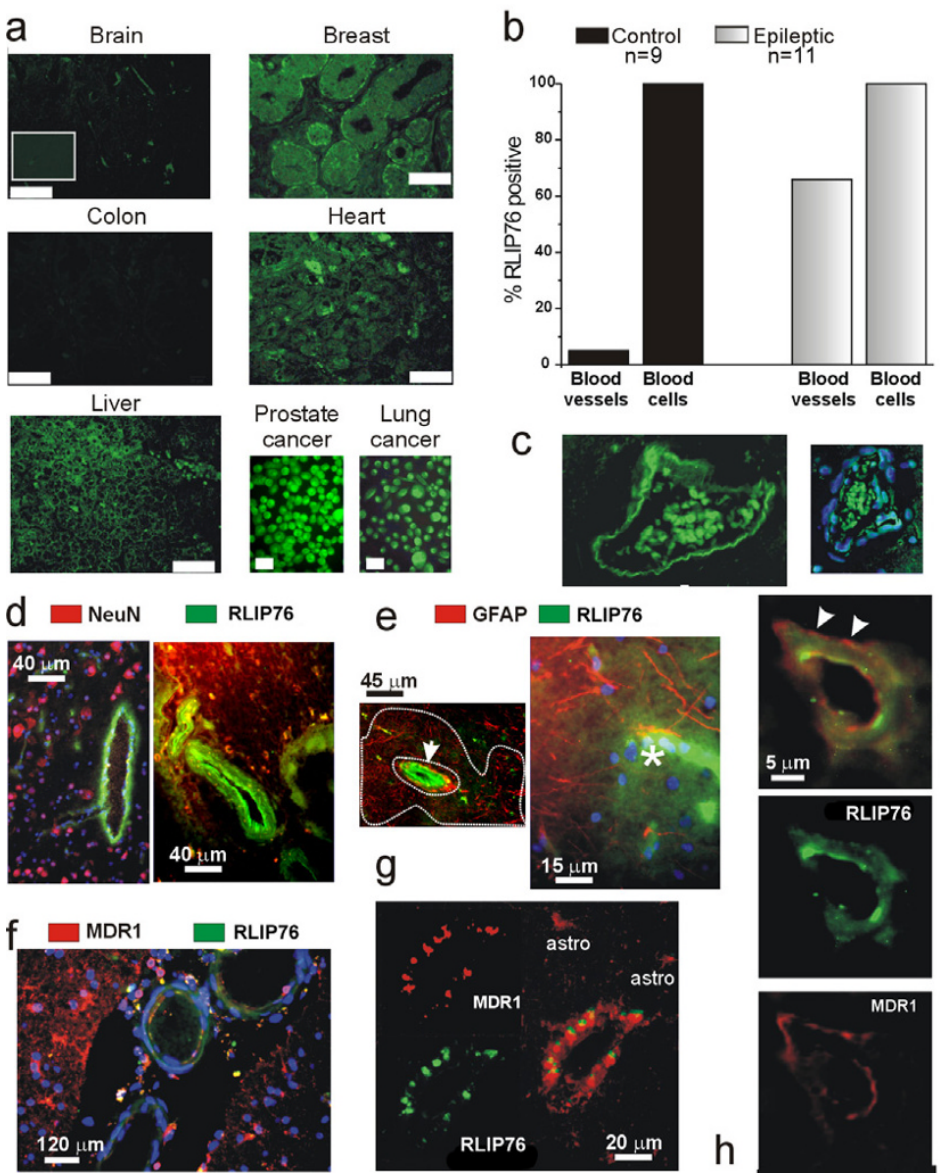

C
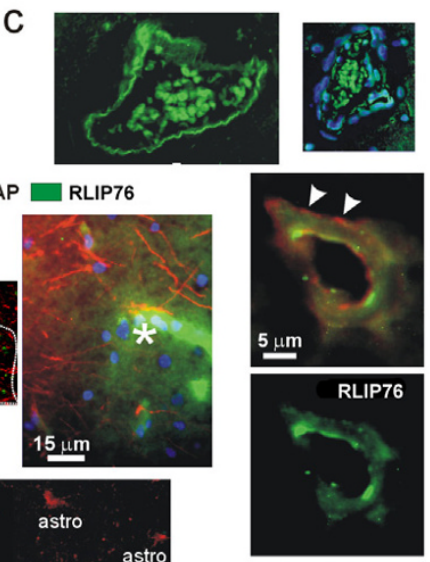

Figure I

Human expression of RLIP76. A) Immunocytochemical detection was performed on tissue arrays with histological sections from normal human tissue. RLIP76 expression was virtually absent from normal brain autopsies; both gray and white matter were analyzed; cumulative data for brain and blood tissue are presented in b). RLIP76 immunoreactivity was observed in breast lobules of primary duct elements, in cardiac myocytes and liver sinusoids. No expression was found in colon tissue. Intense immunoreactivity was present in cell lines of tumor origin. Bars indicate $60 \mu \mathrm{m}$ with the exception of the cell culture data, where the bars reflect $10 \mu \mathrm{m}$. The inset in a) shows a negative control of a brain section incubated with secondary but not primary antibodies. B) Cerebrovascular expression of RLIP76 in epileptic brain. Blood vessels from multiple drug resistant epileptic brain were characterized by high levels of RLIP76 expression. Both vascular and intravascular cells were RLIP76 immunopositive. RLIP76-positive intravascular cells were anucleated and did not react with the nuclear stain DAPI (in blue, C). Note that erythrocytes were found to be RLIP76 immunopositive in both normal and epileptic tissue. RLIP76 is expressed exclusively in epileptic endothelial cells and does not localize to glia or neurons. D) NeuN expression is segregated from RLIP76 immunoreactivity, which is limited to cortical vessels. E) Widespread GFAP immunoreactivity in epileptic brain does not co-localize with RLIP76 (in green). Both large (arrow) and capillary-size (asterisk) vessels express RLIP76. Note the large region of GFAP positive reactive gliosis (limited by a dotted line) characterized by the absence of RLIP76 expression. F) MDRI and RLIP76 co-localize in "epileptic" blood vessels but MDRI expression extends to parenchymal cells. Three large pial vessels are shown to demonstrate the predominant vascular expression of RLIP76. Note that MDRI expression was more predominant in parenchymal glia. G-H) High power demonstration of endothelial coexpression of RLIP76/MDR I. Note that MDR I expression co-localized with RLIP76 expressed at the lumenal surface, while MDRI expression was also observed in RLIP76-negative ablumenal structures reflecting glial endfeet (arrowheads in $\mathrm{H}$ ). We studied a total of $4 \mathrm{I}$ patients, including samples from 6 autopsies. The average age of the patients was $32 \pm 18$ years, range 3 months -59 years old. No data are available on the autopsy material, besides the fact that these were adults of either sex. The non-epileptic patients were either undergoing surgery for aneurysm clipping or to remove arteriovenous or other vascular malformations. None of these patients had seizures prior to surgery or received antiepileptic drug treatment. The surgical epileptic patients studied were resistant to the following drugs: CBZ = 61\%; PHE $=77 \%$; Pentobarbital $=55 \%$; Tompiramate $=$ $50 \%$; valproic acid $=44 \%$; other AEDs, less than $5 \%$. Most patients were resistant to > two drugs; I patients (a 3 months old infant) did not undergo any drug treatment, while another patient ( 8 month old) attempted ketogenic diet treatment). 
capillary endothelial cells, penetrating pial vessels, and larger $(>100 \mu \mathrm{m})$ vessels (Fig. 1d, e, and 1f). In capillary endothelial cells, MDR1 expression was both lumenal (endothelial) and abluminal (glial endfeet), whereas RLIP76 expression appeared to be predominantly lumenal and did not co-localize with GFAP immunoreactivity (Fig. $1 \mathrm{~g}$ and $1 \mathrm{~h}$ ). Additional studies are needed to confirm this finding.

Since the predominant endothelial localization of RLIP76 suggested a strategic role in determining multiple drug resistance to antiepileptic drugs, we tested the ability of RLIP76 to extrude the classic antiepileptic drug PHE [28] (Fig. 2). This was examined in an isolated system consisting of asolectin-cholesterol artificial liposomes reconstituted in the presence of purified human RLIP76 $[23,24]$. Uptake of PHE by liposomes with RLIP76 or without (control) was examined in the presence or absence of ATP. Presence of ATP in the transport medium increased the uptake of ${ }^{14} \mathrm{C}$-PHE by RLIP76-liposomes in a dose dependent fashion, whereas ATP had no effect on uptake by control liposomes (Fig. 2a). We also determined that the intra-vesicular concentration of PHE in control liposomes with or without ATP and in RLIP76 liposomes without ATP were near the extra-vesicular drug-concentration $(1 \mu \mathrm{M})$, while RLIP76-liposomes in the presence of ATP had intra-vesicular PHE concentrations of $5.7 \mu \mathrm{M}$, demonstrating that in the presence of ATP, RLIP76 liposomes are able to concentrate PHE against a gradient, the hallmark of active transport.

Similar findings were obtained when investigating ATPdependent transport of another classic antiepileptic drug carbamazepine (CBZ). While it is commonly believed that PHE is an MDR1 substrate, uncertainty exists on CBZ extrusion by MDR1 $[5,29]$. Uptake of PHE or CBZ by inside-out vesicles was a time dependent process with kinetics consistent with a single compartment filling model (Fig. 2b), and the initial velocity of transport could be reasonably estimated by measuring uptake at $2 \mathrm{~min}$ after addition of ATP. Both antiepileptic drugs (AED) were transported by RLIP7 6 liposomes (Fig. 2d) Initial velocity kinetics performed with varying either substrate (ATP or $\mathrm{CBZ} / \mathrm{PHE}$ ), while holding the other constant showed that the $K_{m}$ for PHE and CBZ was 0.43 and $0.25 \mu \mathrm{M}$ respectively (Fig. 2e) and for ATP $1.33 \mathrm{mM}$ (PHE) and $3.3 \mathrm{mM}$ (CBZ) (Fig. 2c).

We then compared function and levels of expression of RLIP7 6 in non-epileptic brain resected during cerebrovascular surgery unrelated to epileptic pathology or drug resistance vs. epileptic brain. Expression of RLIP7 6 was determined by Western blot of tissue blocks and mRNA analysis in isolated and cultured brain microvascular endothelial cells (Fig. 2f-h). We found that RLIP76
mRNA expression was greater in epileptic brain or endothelial cells isolated from the same tissue and that RLIP76 protein levels correlated with PHE transport activity measured in inside-out vesicles prepared from brain tissue (Fig. 2h).

Functional RLIP76 expression and AED transport activity were further studied in freshly collected human brain samples from epileptic patients. To determine the relative contribution of RLIP76 toward total PHE/CBZ efflux capacity, we examined drug transport in the absence or presence of anti-RLIP76 antibodies [23] in crude membrane vesicles prepared from freshly collected human epileptic brain tissue ( $\mathrm{n}=8$; Fig. $3 \mathrm{a}, \mathrm{b})$. Anti-RLIP76 inhibited total transport of PHE and CBZ by $64 \pm 6$ and 74 $\pm 1.82 \%$ respectively $(\mathrm{p}<0.01)$. When we repeated the same experiments with anti-MDR1 antibodies, we found inhibition by $21 \pm 9$ (PHE) and $13 \pm 1.86$ (CBZ) \%; exposure to both antibodies resulted in a cumulative inhibition. Interestingly, the amount of PHE extrusion by MDR1 determined by antibody-mediated inactivation was comparable to that described in a previous study after pharmacological blockade by XR9576, a specific MDR1 blocker [30]. These findings indicated that RLIP7 6 is the predominant AED transporter in brain tissue.

For the above experiments, we directly obtained vesicles from acutely isolated cortical samples. Under these conditions, culture artifacts are avoided but the individual contribution of a given cell type remains undetectable. To determine the cell type involved in the process of RLIP76mediated PHE extrusion we compared ${ }^{14} \mathrm{C}$-PHE transport in vesicles obtained from endothelial cells and astrocytes isolated and cultured from either control $(n=4)$ or epileptic $(n=6)$ brain [31] (Fig. 3c, d). PHE transport was significantly higher in endothelial cells as compared to astrocytes, and greater in both cell types from epileptic tissues. These data are in agreement with the immunocytochemical results showing predominant expression of RLIP76 in human epileptic endothelial cells and not brain parenchymal cells.

PHE has been described as an MDR1 substrate based on experiments performed on knock out mice lacking Pgp [32]. We performed experiments in RLIP76 ${ }^{+/+}$and RLIP761-C57B mice injected i.p. with PHE ( 33 or $83 \mathrm{mg} / \mathrm{kg}$, 6 animals per group; Fig. 3e). At both doses, brain PHE levels were higher in RLIP76-- mice as compared with RLIP7 $6^{+/+}$ $(\mathrm{p}<0.05)$. However, this was more prominent at the 83 $\mathrm{mg} / \mathrm{kg}$ level. A statistically significant increase in PHE accumulation in brain was observed at both concentrations (Fig. 3f). RLIP76-/- mice were characterized by higher levels of PHE in both brain and serum compared with the wild-type, consistent with a role of RLIP76 in renal excretion of PHE (not shown). To account for this, a group of 

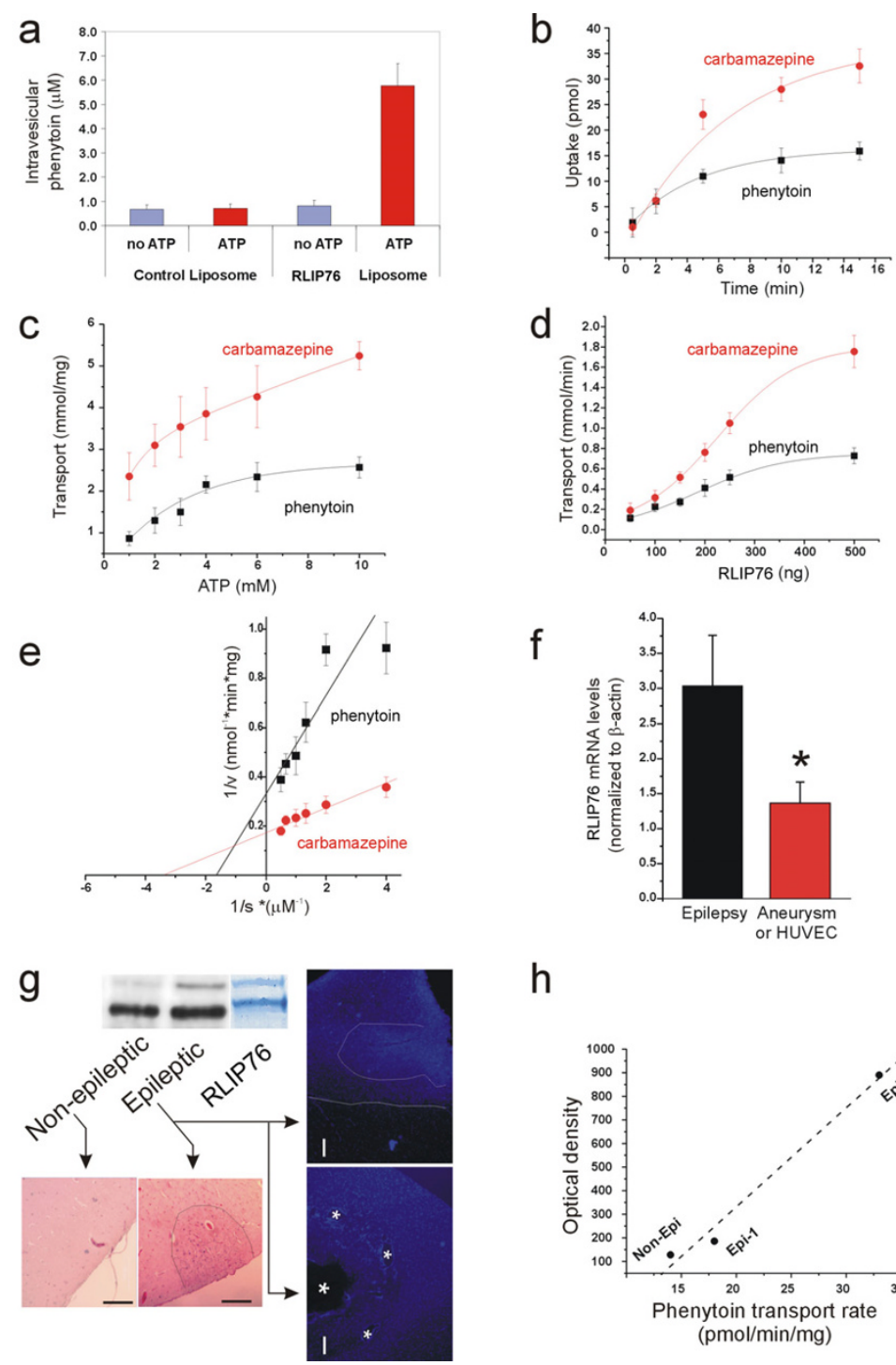

h

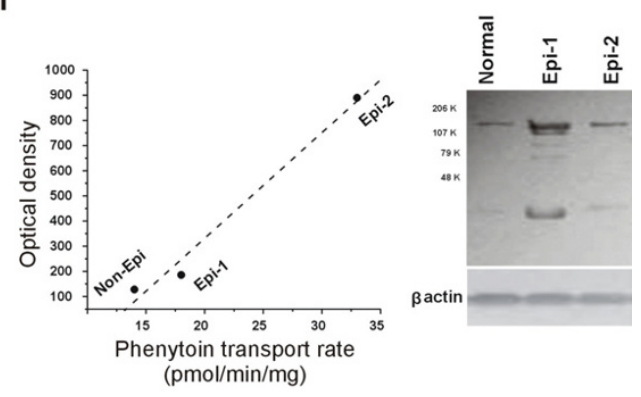

Figure 2

Phenytoin Transport by RLIP76. A) Requirement of both ATP and RLIP76 for increased liposomal uptake of ${ }^{14}$ C-PHE. Experiments in a-e were performed four times and triplicate determinations were performed for each data point. B) Time dependent uptake of ${ }^{14} \mathrm{C}$-PHE and ${ }^{14} \mathrm{C}$-CBZ by RLIP76-proteoliposomes in the presence of $\mathrm{ATP}$. Data were fitted by $\mathrm{y}=$ $\mathrm{y}_{0}+\mathrm{A}_{1} \mathrm{e}^{(-\mathrm{x} / \mathrm{t})}$. C) Saturable kinetics of ${ }^{14} \mathrm{C}-\mathrm{PHE}$ and ${ }^{14} \mathrm{C}-\mathrm{CBZ}$ transport by purified recombinant human RLIP76 with respect to ATP concentrations. Data were fitted by a single exponential. D) Transport of PHE and CBZ by RLIP76-proteoliposomes. Radiolabeled drugs were incubated in the absence or presence of $4 \mathrm{mM}$ ATP with RLIP76 liposomes containing variable amounts of RLIP76. Unless both ATP and RLIP76 were present, drug-uptake was close to the detection limit. Data points were fitted by a Sigmoid $y=A_{2}+\left(A_{1}-A_{2}\right) /\left(I+\exp \left(x-x_{0}\right) / d x\right)$. E) Determination of $K_{m}$ values for RLIP76-mediated transport of ${ }^{14} C$ PHE and ${ }^{14}$ C-CBZ. F) RLIP76 mRNA expression in normal (aneurysm, HUVEC) and "epileptic" endothelial cells isolated from tissue resections [3I,34]. Note that RLIP76 was significantly $(p<0.05)$ increased in endothelial cells isolated from multiple drug resistant patients $(n=6)$ compared to control tissue $(n=8)$. $\mathbf{G})$ Analysis of specimens by Western-blot analysis confirmed these findings. We compared protein expression in dysplastic or normal cortex within the same patient [42,43]. Note that the actively epileptic cortex was characterized by gross abnormality and increased expression of RLIP76. The Coomassie stained band shows the migration pattern of purified human RLIP76 to emphasize the increased levels of signal in both bands. The arrows point to histological sections from the same regions used to isolate protein. Note that abnormal clustering of cells is evident on H\&E stained sections and in neighboring samples stained with DAPI. The bars indicate $100 \mu \mathrm{m}$; the dotted and dashed lines show the extent of abnormal nuclear clustering while the asterisks refer to abnormal vascular structure present in these grossly malformed cortices. H) RLIP76 is up-regulated in epileptic brain and RLIP76 protein expression levels correlate with transport activity in inside-out membrane vesicles prepared from the same tissues. Data were fitted linearly ( $R$ value of 0.99$)$. 


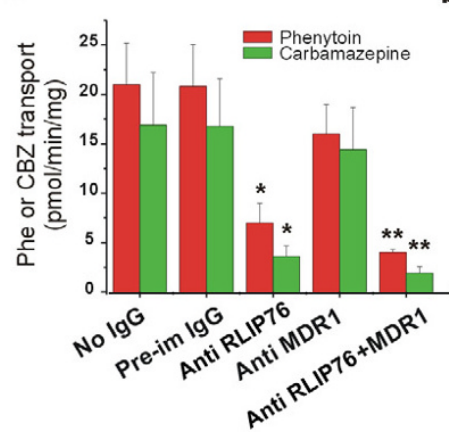

e

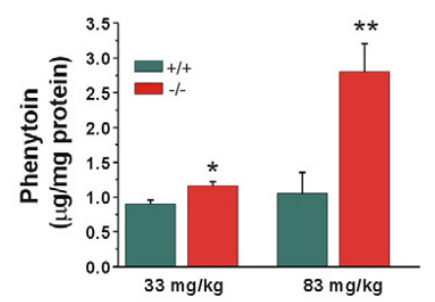

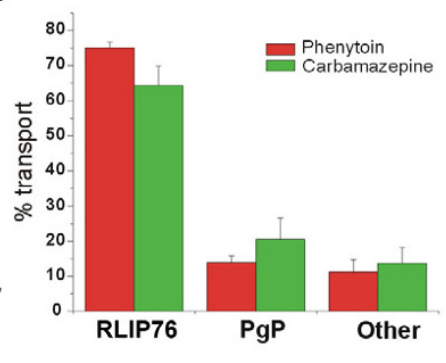

f

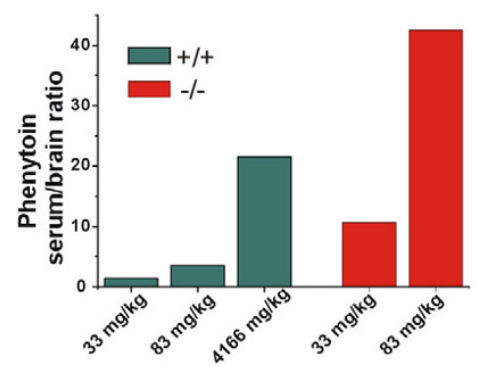

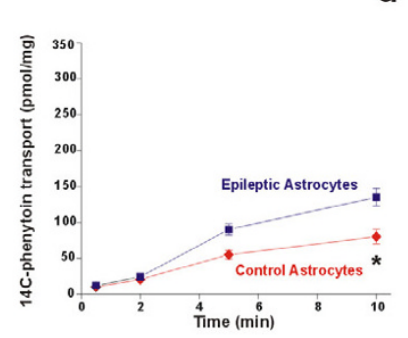

g

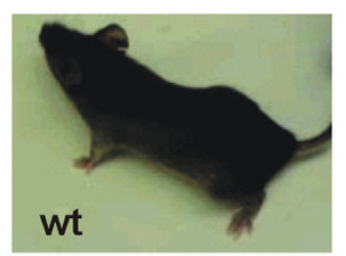

d
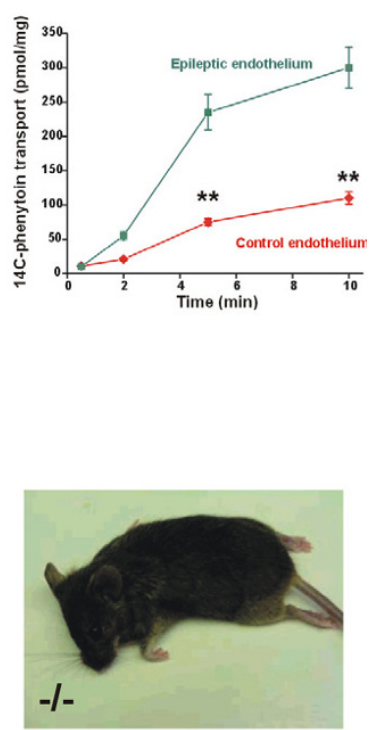

Figure 3

Phenytoin transport in epileptic brain is mediated by RLIP76. A-B) Relative contribution of RLIP76 and MDRI to total AED transport capacity in IOV prepared from brain tissue of non-epileptic, non-multiple drug resistant and multiple drug resistant epileptic patients. This was determined using anti-RLIP76 and anti-MDRI antibodies [23,25]. In this figure, * and ** represent $p<0.05$ and 0.0 I respectively. C-D) Time dependent PHE uptake by IOV prepared from primary cultures of astrocytes or endothelial cells from normal (diamonds) or epileptic brain (squares). E-F) Brain PHE levels in RLIP76 ${ }^{+/+}$and RLIP76-/mice $2 \mathrm{~h}$ after IP administration of Phosphenytoin at 33 or $83 \mathrm{mg} / \mathrm{kg}$ ( 3 animals/group). G) After exposure to the antiepileptic drug, RLIP76 ${ }^{+/+}$animals (left panel) appeared relatively unaffected compared with RLIP76-/- mice (right panel) where a severe neurological toxicity including extensor posturing, lethargy and status epilepticus were observed.

wild-type animals was injected with elevated (4166 mg/ $\mathrm{kg}$ ) doses of PHE to achieve serum levels comparable to those seen in knock out animals injected with much lower quantities (83 mg/kg). RLIP76\% mice demonstrated greater neurotoxicity after administration of PHE; side effects in these animals included lethargy and status-epilepticus (Fig. 3g).

\section{Conclusion}

Taken together, our results show that RLIP76 is an important PHE and CBZ transporter at the human blood brain barrier, and its expression is increased in the BBB from patients with drug-resistant epilepsy. RLIP76 fulfilled many of the predicted properties for a mediator of CNS pharmacoresistance, including: 1) presence at the anatomical interface between brain and blood; 2) transport of the antiepileptic drugs PHE and CBZ; 3) functional expression in brain microvascular endothelial cells but not in parenchymal glia or neurons; and 4) increased CNS accumulation of PHE in RLIP76\%- mice. These results also demonstrate for the first time that the putative mediator of multiple drug resistance in epilepsy, MDR1 [33], is in fact overshadowed in potency by another ATP-dependent transporter. Our results are also in accord with previous reports which questioned the relevance of MDR1 as a multiple drug resistance mechanism, while rather suggesting a role in neuroglial protection [10]. We also confirmed that CBZ is a poor MDR1 substrate [34].

Several important questions remain unanswered. For example, is the widespread distribution of MDR1, MRPs (in particular MRP2 [35]) and RLIP76 in epileptic brain also linked to the pathology itself? Are these transporters expressed as a response to a hostile environment or are they regulated exclusively by chemotherapy? Both MDR1 and MRP are involved in cell survival, and recent evidence by this laboratory [8-10] have shown that apoptotic mechanisms are lacking in epileptic brain. Interestingly, the original proposed role for RLIP76 was indeed that of a molecule involved in detoxification or protection of cells living in hostile environments [36,37]. More recently, Yadav et al. have confirmed a dual role for 
Table I: Human Tissue Donor Information

\begin{tabular}{|c|c|c|c|c|c|}
\hline ID & Age & Sex & Notes & AED failed & Use \\
\hline I & 0.8 & $M$ & EPi- Hemispherectomy & None & WB \\
\hline 2 & 0.3 & M & Epi-Hemispherectomy & Ketogenic Diet & WB, AED transport studies \\
\hline 3 & 57 & $\mathrm{~F}$ & Temporal Lobe Epilepsy & PHE, CBZ,TPM & WB \\
\hline 4 & 33 & $\mathrm{~F}$ & Control (AVM) & None & WB \\
\hline 5 & 61 & $\mathrm{~F}$ & Temporal Lobe epilepsy & VAL,CBZ,TPB & WB, AED transport studies \\
\hline 6 & 30 & M & Control Parasaggital Cist & None & WB, AED transport studies \\
\hline 7 & 0.9 & $\mathrm{~F}$ & Frontal/Parietal Epilepsy & VAL, PBT, TPM & WB \\
\hline 8 & 14 & M & Temporal Lobe Epilepsy & CBZ, Keppra, PBT,TPM, VAL & WB \\
\hline 9 & 42 & M & Temporal Lobe Epilepsy & VAL, PBT, primidone, tiagabine, & AED transport studies \\
\hline 10 & 27 & $\mathrm{~F}$ & Temporal Lobe Epilepsy & PHE,VAL,gabapentin,CBZ, TPM & AED transport studies \\
\hline II & 7 & M & R. Lateral Parietal/Occipital/Temporal Lobes & PBT, PHE, TPM, CBZ, DZP, LMT & AED transport studies \\
\hline 12 & 14 & M & Temporal Lobe Epilepsy & VAL,Keppra, CBZ, other & AED transport studies \\
\hline 13 & 31 & $\mathrm{~F}$ & Temporal Lobe Epilepsy & gabapentin, CBZ,VAL,PHE,PBT & AED transport studies \\
\hline 14 & 60 & $\mathrm{~F}$ & Temporal Lobe Epilepsy & PBT, MBL, TGL, DPT, VLM, MSL, FBT & In vitro cells $A E D$ \\
\hline 15 & 43 & $\mathrm{~F}$ & Focal Epi & N/A & In vitro cells $A E D$ \\
\hline 16 & 56 & M & Focal Epi & PHE, PBT, CBZ, VAL, ETS & In vitro cells $A E D$ \\
\hline 17 & 43 & $\mathrm{~F}$ & Temporal Lobe Epilepsy & PHE, CBZ, VAL, GBP & mRNA analysis \\
\hline 18 & 40 & $\mathrm{~F}$ & Control (Aneurysm) & NONE & mRNA analysis \\
\hline 20 & 58 & $\mathrm{~F}$ & Focal Epi & PHE, PBT, VAL, PRM, FBT, GBP, TPM & mRNA analysis \\
\hline 21 & 35 & $M$ & Temporal Lobe Epilepsy & PHE, CBZ, VAL, PRM, VGB & mRNA analysis \\
\hline 22 & 28 & $M$ & Temporal Lobe Epilepsy & PHE, PBT, CBZ, VAL, TPM, CZP, GBP & mRNA analysis \\
\hline 23 & 38 & M & Temporal Lobe Epilepsy & PHE, CBZ, VAL, FBM, GBP & mRNA analysis \\
\hline 24 & 39 & M & Temporal Lobe Epilepsy & PHE, PBT, VAL, PRM, MSD & mRNA analysis \\
\hline 25 & 31 & M & Temporal Lobe Epilepsy & PHE, PBT, VAL, TPM & mRNA analysis \\
\hline 26 & 23 & M & Temporal Lobe Epilepsy & PHE, PBT, CBZ, VAL, GBP & mRNA analysis \\
\hline 27 & 45 & $\mathrm{~F}$ & Control (Aneurysm) & NONE & mRNA analysis \\
\hline 28 & 22 & $\mathrm{~F}$ & Control (Aneurysm) & NONE & mRNA analysis \\
\hline 36 & 7 & M & Temporal Lobe Epilepsy & PHE, CBZ, VAL, GBP & ICC \\
\hline 37 & 28 & $\mathrm{~F}$ & Temporal Lobe Epilepsy & PHE, PBT, CBZ, VAL & ICC \\
\hline 38 & 7 & M & Temporal Lobe Epilepsy & $?$ & ICC \\
\hline 39 & 4 & $\mathrm{~F}$ & Frontal and Parietal Epilepsy & PHE, CBZ, VAL, PRM, & ICC \\
\hline 40 & 8 & $\mathrm{~F}$ & Temporal lobe epilepsy & $\mathrm{CBZ}, \mathrm{PHE}, \mathrm{VAL}$ & ICC \\
\hline 41 & 24 & M & Control (AVM) & NONE & ICC \\
\hline 42 & I & $M$ & Frontal Epilepsy & CBZ, PHE, VAL & ICC \\
\hline 43 & 25 & $M$ & Temporal Lobe Epilepsy & Phe CBZ & ICC \\
\hline 44 & 1 & M & Hemispherectomy & None & ICC \\
\hline 45 & 23 & $\mathrm{~F}$ & Contol (AVM) & None & ICC \\
\hline 46 & 23 & M & Temporal lobe epilepsy & gabapentin, CBZ,VAL,PHE, & ICC \\
\hline 47 & 23 & M & Control (AVM) & None & ICC \\
\hline 48 & 7 & $M$ & TSC & $?$ & ICC \\
\hline 49 & 3 & $F$ & Epilepsy Right Hemi & $?$ & ICC \\
\hline 50 & & & Autopsy & & ICC \\
\hline 51 & & & Autopsy & & ICC \\
\hline 52 & & & Autopsy & & ICC \\
\hline 53 & & & Autopsy & & ICC \\
\hline 54 & & & Autopsy & & ICC,WB \\
\hline 55 & & & Autopsy & & ICC,WB \\
\hline
\end{tabular}

RLIP76, consisting of anti-apoptotic and drug resistance functions [38]. Thus, purely on the bases of overall function, MDR1 and RLIP7 6 are indistinguishable. It is possible that multiple drug resistance molecules, in addition to cooperating in drug extrusion, also play a role in the control of cellular homeostasis.
In conclusion, we report a novel, non-ABC transporter mediated mechanism of antiepileptic drug resistance that may synergistically cooperate with MDR1. The relative contribution of each transporter as determined in vitro and ex situ suggests a predominant role for RLIP76. Our results are consistent with a predominant role of the 
blood-brain barrier in determining multiple drug resistance to antiepileptic drugs.

\section{Methods \\ Reagents}

CNBr-activated Sepharose 4B, 1-chloro-2,4-dinitrobenzene (CDNB), PMSF, $\beta$-mercaptoethanol (BME), EGTA, EDTA, ATP, butylated hydroxytoluene (BHT), and polidocanol $\left(\mathrm{C}_{12} \mathrm{E}_{9}\right)$, were purchased from Sigma Chemical Co., St. Louis, MO. DE-52 (diethylaminoethyl cellulose) anion exchanger was purchased from Whatman International Ltd. Maidstone, England. Bio-Beads (SM-2 adsorbent) and Chelex-100 resin were purchased from Bio-Rad Laboratories (Hercules, CA). Tryptone and yeast extract for preparing culture media were purchased from DIFCO laboratories, Detroit, MI. PHE was purchased from Pfizer New York, NY. $\left[4-{ }^{14} \mathrm{C}\right]-5,5$-diphenylhydantoin (specific activity $49.37 \mathrm{mCi} / \mathrm{mmol}$ ) and $\left[{ }^{14} \mathrm{C}\right]-\mathrm{CBZ}$ (specific activity $22.6 \mathrm{mCi} / \mathrm{mmol}$ ) were purchased from Perkin Elmer Life Sciences, Boston, MA and Sigma Chemical Co., St. Louis, $\mathrm{MO}$, respectively. Source of anti-RLIP76 IgG used in these studies was the same as previously described [39]. DNPSG and DNP-SG-Sepharose-4B affinity resin were prepared as previously described [39].

\section{Tissue procurement and inside-out vesicle preparation (IOV)}

Human subjects (see Table 1 for details) were used for these studies as donors of tissue samples. The investigation conforms to the principles outlined in the Declaration of Helsinki. For freshly isolated surgical samples, patient consent was obtained as per the Institutional Review Board instructions before collection of the specimens; autopsy materials were obtained from organ donors. Endothelial cells and glia were isolated from brain specimens from patients undergoing a temporal lobectomy to relieve medically intractable seizures ( $\mathrm{n}=$ 12) or cortices of patients undergoing surgery for removal of vascular malformations $(n=3)$. Tissue from autopsy material was used for Fig. 1a. Blood vessels were isolated from resected tissue by manually pulling out a combination of penetrating pial and superficial pial vessels. The methods are described in detail elsewhere [9,34]. The plasma membrane vesicles of human brain cells were prepared as described elsewhere $[21,23,25]$. Briefly, the cells were separated form the suspension buffer by centrifugation and lysed by incubation in hypotonic buffer $(0.5 \mathrm{mM}$ sodium phosphate, $\mathrm{pH} 7.0$, containing $0.1 \mathrm{mM}$ EDTA and $0.1 \mathrm{mM}$ PMSF for $1.5 \mathrm{~h}$, followed by homogenization. After centrifugation of the homogenate at $12,000 \mathrm{~g}$ (10 $\min$ at $4^{\circ} \mathrm{C}$ ), the postnuclear supernatant was further centrifuged at $100,000 \mathrm{~g}$ for $40 \mathrm{~min}$ at $4^{\circ} \mathrm{C}$. The resulting pellet was suspended in the reconstitution buffer $(250 \mathrm{mM}$ sucrose-10 mM Tris- $\mathrm{HCl}, \mathrm{pH} 7.4$ ) homogenized with tight fitting Dounce homogenizer and layered over 38\% sucrose in $5 \mathrm{mM}$ Hepes-KOH, pH 7.4. After centrifugation at $28,000 \mathrm{~g}$ for $2 \mathrm{~h}$ at $4^{\circ} \mathrm{C}$ the interphases were collected, washed by centrifugation in the reconstitution buffer $(100,000 \mathrm{~g})$, and passed 20 times through a 27 -gauge needle for vesicle formation.

\section{Anti-RLIP76 and anti-MDRI antibodies}

Goat-anti-human Pgp antibody C-19 was purchased from Santa Cruz Biotech, CA. Polyclonal rabbit-anti-RLIP76 IgG as well as pre-immune IgG were prepared and purified as described previously $[39,40]$. Briefly, recombinant human RLIP7 6 expressed in E. coli and purified by DNPSG-Sepharose affinity purification as previously described [39] was injected (75 $\mu \mathrm{g}$ ) into New Zealand White rabbit after obtaining preimmune serum. After booster doses of $50 \mu \mathrm{g}$ each at two week intervals, post-immune serum was obtained. The IgG fraction from pre- and post-immunized, heat-inactivated serum was purified by DE-52 anion exchange chromatography, followed by protein-ASepharose affinity chromatography. The purity of the antibody was checked by SDS-PAGE as well as Western blotting against goat anti-rabbit IgG. Aliquots of the antibody were stored at $-86^{\circ} \mathrm{C}$ and checked regularly by aerobic and anaerobic cultures for contamination. The specificity of anti-RLIP76 and other antibodies has been stringently established: purified recombinant RLIP7 6 used for raising polyclonal antibodies was demonstrated to be homogenous by amino acid composition analysis demonstrating amino acid yields within $96 \%$ of those expected according to its sequence SELDI-MS demonstrating a pattern of $[\mathrm{M}+\mathrm{H}]$ peaks consistent with homogenous preparations of RLIP76 [39].

\section{Immunocytochemistry}

To investigate the expression of RLIP76 protein and its localization in both various human tissues and in human epileptic brain, slide mounted sections of $10 \mu \mathrm{m}$ thickness from frozen brain tissue were labeled as previously described [8,9]. Purified anti-RLIP76 IgG was used as primary antibody. FITC conjugated purified donkey anti-rabbit IgG (Jackson Immunoresearch Laboratories, West Grove, Pennsylvania) was the secondary antibody.

\section{Preparation of liposomes containing purified recombinant RLIP76}

The 1968 bp full length open reading frame cDNA of human RLIP76 was cloned from a $\lambda$ gt11 human bone marrow library by immuno-screening, using anti-DNP-SG ATPase antibodies and was subcloned into the prokaryotic expression vector, pET30a(+) (Novagen, Madison, Wisconsin), creating the pET30-RLIP76 plasmid free of extraneous sequences. This plasmid was transformed into E. coli BL21 (DE3). Protein was expressed in E. coli BL21 (DE3) grown at $30^{\circ} \mathrm{C}$ after induction with $0.4 \mathrm{mM}$ IPTG [39]. DNP-SG affinity chromatography was used as 
described previously $[39,40]$ to obtain purified RLIP76. ATPase activity was performed as previously described to monitor purification [26]. Purity was checked by SDSPAGE, Western blot analysis and amino acid composition analysis as previously described [39]. Purified protein was dialyzed against liposome reconstitution buffer $(10 \mathrm{mM}$ Tris-HCl, $\mathrm{pH} 7.4,2 \mathrm{mM} \mathrm{MgCl} 2,1 \mathrm{mM}$ EGTA, $100 \mathrm{mM}$ $\mathrm{KCl}, 40 \mathrm{mM}$ sucrose, $2.8 \mathrm{mM} \mathrm{BME}, 0.05 \mathrm{mM}$ BHT, and $0.025 \%$ polidocanol). An aqueous emulsion of soybean asolectin $(40 \mathrm{mg} / \mathrm{ml})$ and cholesterol $(10 \mathrm{mg} / \mathrm{ml})$ was prepared in the reconstitution buffer by sonication. This emulsion was diluted 10 fold by addition of dialyzed RLIP7 6 in reconstitution buffer to achieve a final RLIP76 concentration of $0.1 \mathrm{mg} / \mathrm{ml}$. The reaction mixture was sonicated at $15 \mathrm{~s}$ at $50 \mathrm{~W}$. Vesiculation was initiated by addition of SM-2 Bio-beads $(200 \mathrm{mg} / \mathrm{ml}$ ) pre-equilibrated in the reconstitution buffer (without polidocanol). Vesiculation was carried out for $4 \mathrm{~h}$ at $4{ }^{\circ} \mathrm{C}$, followed by removal of SM-2 Bio-beads by centrifugation. The vesicles were collected and analyzed for protein content, transport activity, and microbial contamination. Control vesicles to measure non-specific transport, were prepared using an equal amount of crude protein from $E$. coli not expressing RLIP76.

\section{Transport studies}

For transport studies, crude membrane inside-out vesicles (IOV) were prepared from different brain tissues and cells by the method as previously described $[23,25]$. Briefly, stock solutions of $40 \mathrm{mM} \mathrm{MgCl}_{2}$ and $40 \mathrm{mM}$ of ATP were prepared in buffer containing $40 \mathrm{mM}$ sucrose and $10 \mathrm{mM}$ Tris-HCl, $\mathrm{pH}$ 7.4. The reaction mixture $(120 \mu \mathrm{L})$ consisted of IOV protein $(80 \mu \mathrm{g}), 10 \mathrm{mM}$ Tris- $\mathrm{HCl}, \mathrm{pH} 7.4,40 \mathrm{mM}$ sucrose, $4 \mathrm{mM} \mathrm{MgCl}$ and appropriate volume of radiolabeled ${ }^{14} \mathrm{C}$-PHE and ${ }^{14} \mathrm{C}$-CBZ were added to attain a final concentration of $1 \mu \mathrm{M}$. To start the reaction, buffer with or without ATP was added to achieve a final concentration of 0 or $4 \mathrm{mM}$ ATP. The uptake was stopped by rapid filtration of a fixed aliquot $(30 \mu \mathrm{L})$ of the reaction mixture through 96 well nitrocellulose plates $(0.45 \mu \mathrm{m}$ pore size). After filtration, the bottoms of the nitrocellulose membranes were blotted dry with filter paper and punched out, and the associated radioactivity was measured by placing in liquid scintillation counting vials. Scintillation vials were vortexed thoroughly, allowed standing for $1 \mathrm{~h}$ at room temperature, and counted in a liquid scintillation counter. Each determination was performed in triplicate. ATPdependent uptake of ${ }^{14} \mathrm{C}$-PHE and ${ }^{14} \mathrm{C}$-CBZ were determined by subtracting the radioactivity of the control without ATP from that of the experimental containing ATP and the transport was calculated in terms of $\mathrm{pmol} / \mathrm{min} / \mathrm{mg}$ protein.

\section{cDNA array and mRNA}

The details of the tissue culture procedures and mRNA extraction have been described previously [5]. Briefly, surgically obtained specimens were washed in phosphate buffered saline (PBS) and incubated in collagenase type II ( $2 \mathrm{mg} / \mathrm{ml}$, Worthington chemicals) at $37^{\circ} \mathrm{C}$ for $20 \mathrm{~min}$ to dissociate the endothelial cells. Collagenase was then washed off with the medium used for growing ECs $(1.5 \mathrm{~g} /$ $100 \mathrm{ml}, \mathrm{MCDB} 105$ supplemented with Endothelial Cell Growth Supplement, $15 \mathrm{mg} / 100 \mathrm{ml}$, heparin 800 units/ $100 \mathrm{ml}, 10 \%$ fetal bovine serum, and penicillin/streptomycin 1\%, Sigma chemicals), and ECs were harvested using a sterile cotton swab soaked in the medium. EC stained positive for Von Willebrand factor and were negative for glial fibrillary acidic protein. ECs were purged from the culture dishes by gentle enzymatic dissociation (collagenase) and collected by centrifugation. Equal amounts of the pellet were used for total RNA isolation and protein extraction. Total RNA was extracted with the Trizol reagent (Gibco Labs). Integrity of the isolated RNA was confirmed by agarose formaldehyde gels. For gene expression analysis, human GENEFILTERS ${ }^{\text {тм }}$ (Research Genetics Inc., Huntsville, Alabama) were used for this study. Each filter membrane contains approximately 4,000 known human genes. ${ }^{33} \mathrm{P}$-dCTP was used to label probe used for hybridization to produce clean and sharp signals, as recommended by the manufacturer.

\section{RLIP76 knockout animals}

RLIP76+/- heterozygous knockout animals were commissioned from Lexicon genetics, and prepared by the strategy described previously [41]. Briefly, C57B mice (12 wk old), born of $R L I P 76^{+/-} \times R L I P 76^{+/-}$mating, were genotyped by PCR strategy. We generated C57B mice which carry heterozygous (+/-) or homozygous (-/-) disruption of the RLIP76 gene, and established colonies of RLIP76+/ +, RLIP76+/-, and RLIP76-/- C57B mice by segregation and mating of animals based on genotyping by polymerase chain reaction (PCR) on tail DNA. Western-blot analysis of mouse tissues using anti-RLIP7 6 antibodies confirmed decreased RLIP76 levels in the RLIP76+/mouse, and its absence in tissues from the RLIP76-/mouse [41]. Consistent with the observed function of RLIP76 as a transporter of GS-E and doxorubicin (DOX) in cell culture studies $[23,25]$, GS-E and DOX transport in membrane vesicles was decreased in a stepwise fashion from the RLIP76+/+, to RLIP76+/-, to RLIP76-/- mice [41].

\section{Measurement of PHE concentration in wild type and RLIP76 knockout mouse serum and brain tissues}

Twelve week old C57B mice born of heterozygous $\times$ heterozygous mating were genotyped by PCR on mouse tail DNA using forward, reverse and LTR primers [41]. PHE measurements were performed on 5 wild type (RLIP76 $6^{+/+}$) and 5 RLIP76 knockout (RLIP76\%) animals sacrificed $2 \mathrm{~h}$ 
after a single i.p.-injection of phosphenytoin or PHE. A $10 \%$ homogenate of mouse brain tissues was prepared and centrifuged at $28,000 \times \mathrm{g}$ for $45 \mathrm{~min}$ at $4{ }^{\circ} \mathrm{C}$. PHE levels in homogenate and plasma was measured using the Dade Behring Clinical Multichannel Analyzer with the PHE Flex ${ }^{\oplus}$ reagent cartridge, a method based on PETINIA technology.

\section{Abbreviations used}

RALBP1, official human genome designation for human Ral-binding protein-1, synonymous with RALBP1, and homologous to rat RALBP1 and mouse RIP1. We refer to the mouse, rat and human proteins as RLIP76 in the present communication; AED, anti-epileptic drug; $\mathrm{BBB}$, blood-brain barrier; CBZ, carbamazepine; EC, endothelial cells; GSH, glutathione; GS-E, glutathione electrophile conjugates; DOX, doxorubicin; MCDB, modified Czapek Dox broth; PHE, phenytoin.

\section{Authors' contributions}

Designed the study, participated in its design and coordination and helped to draft the manuscript: Sanjay Awasthi, Damir Janigro

Performed pharmacological experiments, including knock out animal studies: Sharad S. Singhal

Contributed to designing of pharmacological experiments and assisted in the writing of the discussion section: Yogesh C. Awasthi

Performed immunocytochemical, mRNA, and Western blotting analysis: Kerri L Hallene, Vince Fazio, Luca Cucullo, Gabriele Dini

\section{Acknowledgements}

This work was supported in part by the National Institutes of Health $(\mathrm{NIH}-$ NS43284, NIH-HL5 I6I 4, NIH-NS465I3 and NIH-NS38I95) to DJ and ES 012171 to YCA and CA 77495 and CA 104661 to SA. We would also like to thank Dr. William Bingaman, MD, the section head of Epilepsy Surgery at the Cleveland Clinic Foundation for expertise in procuring human tissue for this study.

\section{References}

I. Sander JW: The problem of the drug-resistant epilepsies. Novartis Found Symp 2002, 243:4-12.

2. Sisodiya SM: Mechanisms of antiepileptic drug resistance. Curr Opin Neurol 2003, 16:197-201.

3. Begley DJ: ABC transporters and the blood-brain barrier. Curr Pharm Des 2004, 10:1295-1312.

4. Schinkel AH, Wagenaar E, Mol CA, van Deemter L: P-glycoprotein in the blood-brain barrier of mice influences the brain penetration and pharmacological activity of many drugs. J Clin Invest 1996, 97:2517-2524.

5. Owen A, Pirmohamed M, Tettey JN, Morgan P, Chadwick D, Park BK: Carbamazepine is not a substrate for P-glycoprotein. $\mathrm{Br} J \mathrm{Clin}$ Pharmacol 200I, 5 I:345-349.

6. Weiss J, Kerpen C], Lindenmaier H, Dormann SM, Haefeli WE: Interaction of antiepileptic drugs with human P-glycoprotein in vitro. J Pharmacol Exp Ther 2003, 307:262-267.
7. Doran A, Obach RS, Smith BJ, Hosea NA, Becker S, Callegari E, Chen C, Chen X, Choo E, Cianfrogna J, Cox LM, Gibbs JP, Gibbs MA, Hatch H, Hop CE, Kasman IN, Laperle J, Liu J, Liu X, Logman M, Maclin D, Nedza FM, Nelson F, Olson E, Rahematpura S, Raunig D, Rogers S, Schmidt K, Spracklin DK, Szewc M, Troutman M, Tseng E, Tu M, Van Deusen JW, Venkatakrishnan K, Walens G, Wang EQ, Wong D, Yasgar AS, Zhang C: The impact of P-glycoprotein on the disposition of drugs targeted for indications of the central nervous system: evaluation using the MDRIA/IB knockout mouse model. Drug Metab Dispos 2005, 33:165- 174 [http://PM: I5502009].

8. Marroni M, Marchi N, Cucullo L, Abbott NJ, Signorelli K, Janigro D: Vascular and parenchymal mechanisms in multiple drug resistance: a lesson from human epilepsy. Curr Drug Targets 2003, 4:297-304.

9. Marroni M, Agarwal M, Kight K, Hallene K, Hossain M, Cucullo L, Signorelli K, Namura S, Janigro D: Relationship between expression of multiple drug resistance proteins and p53 tumor suppressor gene proteins in human brain astrocytes. Neuroscience 2003, I $21: 605-617$

10. Marchi N, Hallene KL, Kight KM, Cucullo L, Moeddel G, Dini G, Bingaman W, Vezzani A, Janigro D: Significance of MDRI and multiple drug resistance in refractory human epileptic brain. $B M C$ Med 2004, 2:37.

II. Sills GJ, Mohanraj R, Butler E, McCrindle S, Collier L, Wilson EA, Brodie MJ: Lack of association between the C3435T polymorphism in the human multidrug resistance (MDRI) gene and response to antiepileptic drug treatment. Epilepsia 2005, 46:643-647.

12. Kwan P, Brodie MJ: Potential role of drug transporters in the pathogenesis of medically intractable epilepsy. Epilepsia 2005, 46:224-235.

13. Maines LW, Antonetti DA, Wolpert EB, Smith CD: Evaluation of the role of $\mathrm{P}$-glycoprotein in the uptake of paroxetine, clozapine, phenytoin and carbamazapine by bovine retinal endothelial cells. Neuropharmacology 2005, 49:610-617.

14. Park SH, Weinberg RA: A putative effector of Ral has homology to Rho/Rac GTPase activating proteins. Oncogene 1995, I I:2349-2355.

15. Jullien-Flores $V$, Mahe $Y$, Mirey $G$, Leprince $C$, Meunier-Bisceuil B, Sorkin A, Camonis JH: RLIP76, an effector of the GTPase Ral, interacts with the AP2 complex: involvement of the Ral pathway in receptor endocytosis. J Cell Sci 2000, II3 ( Pt 16):2837-2844

16. Cantor SB, Urano T, Feig LA: Identification and characterization of Ral-binding protein I, a potential downstream target of Ral GTPases. Mol Cell Biol 1995, I 5:4578-4584.

17. Jullien-Flores $V$, Dorseuil O, Romero F, Letourneur F, Saragosti $S$, Berger R, Tavitian A, Gacon G, Camonis JH: Bridging Ral GTPase to Rho pathways. RLIP76, a Ral effector with CDC42/Rac GTPase-activating protein activity. J Biol Chem 1995, 270:22473-22477.

18. Quaroni A, Paul EC: Cytocentrin is a Ral-binding protein involved in the assembly and function of the mitotic apparatus. J Cell Sci 1999, I I 2 ( Pt 5):707-7I8.

19. Rosse C, L'Hoste S, Offner N, Picard A, Camonis J: RLIP, an effector of the Ral GTPases, is a platform for CdkI to phosphorylate epsin during the switch off of endocytosis in mitosis. J Biol Chem 2003, 278:30597-30604.

20. Sharma R, Sharma A, Yang Y, Awasthi S, Singhal SS, Zimniak P, Awasthi YC: Functional reconstitution of Ral-binding GTPase activating protein, RLIP76, in proteoliposomes catalyzing ATP-dependent transport of glutathione conjugate of 4hydroxynonenal. Acta Biochim Pol 2002, 49:693-70I.

21. Sharma R, Singhal SS, Cheng J, Yang Y, Sharma A, Zimniak P, Awasth S, Awasthi YC: RLIP76 is the major ATP-dependent transporter of glutathione-conjugates and doxorubicin in human erythrocytes. Arch Biochem Biophys 2001, 391:171-179.

22. Sharma R, Singhal SS, Wickramarachchi D, Awasthi YC, Awasthi S: RLIP76 (RALBPI)-mediated transport of leukotriene C4 (LTC4) in cancer cells: implications in drug resistance. Int J Cancer 2004, I I 2:934-942.

23. Awasthi S, Singhal SS, Singhal J, Yang Y, Zimniak P, Awasthi YC: Role of RLIP76 in lung cancer doxorubicin resistance: III. AntiRLIP76 antibodies trigger apoptosis in lung cancer cells and synergistically increase doxorubicin cytotoxicity. Int J Oncol 2003, 22:72I-732. 
24. Awasthi S, Singhal SS, Sharma R, Zimniak P, Awasthi YC: Transport of glutathione conjugates and chemotherapeutic drugs by RLIP76 (RALBPI): a novel link between G-protein and tyrosine kinase signaling and drug resistance. Int J Cancer 2003, 106:635-646.

25. Awasthi S, Singhal SS, Singhal J, Cheng J, Zimniak P, Awasthi YC: Role of RLIP76 in lung cancer doxorubicin resistance: II. Doxorubicin transport in lung cancer by RLIP76. Int J Oncol 2003, 22:713-720

26. Singhal SS, Singhal J, Sharma R, Singh SV, Zimniak P, Awasthi YC, Awasthi S: Role of RLIP76 in lung cancer doxorubicin resistance: I. The ATPase activity of RLIP76 correlates with doxorubicin and 4-hydroxynonenal resistance in lung cancer cells. Int J Oncol 2003, 22:365-375.

27. Stuckler D, Singhal J, Singhal SS, Yadav S, Awasthi YC, Awasthi S: RLIP76 transports vinorelbine and mediates drug resistance in non-small cell lung cancer. Cancer Res 2005, 65:99/-998.

28. Treiman DM, Woodbury DM: Absorption, distribution and excretion of phenytoin. Edited by: Levy RH, Mattson RH and Meldrum BS. Raven Press; 1998.

29. Potschka H, Fedrowitz M, Loscher W: P-glycoprotein and multidrug resistance-associated protein are involved in the regulation of extracellular levels of the major antiepileptic drug carbamazepine in the brain. Neuroreport 200I, I 2:3557-3560.

30. Martin C, Berridge G, Mistry P, Higgins C, Charlton P, Callaghan R: The molecular interaction of the high affinity reversal agent XR9576 with P-glycoprotein. Br J Pharmacol I999, I 28:403-4II.

3I. Marroni M, Kight KM, Hossain M, Cucullo L, Desai SY, Janigro D: Dynamic in vitro model of the blood-brain barrier. Gene profiling using cDNA microarray analysis. Methods Mol Med 2003, 89:419-434

32. Schinkel AH: P-Glycoprotein, a gatekeeper in the blood-brain barrier. Adv Drug Deliv Rev 1999, 36:179-194.

33. Abbott NJ, Khan EU, Rollinson CM, Reichel A, Janigro D, Dombrowski SM, Dobbie MS, Begley DJ: Drug resistance in epilepsy: the role of the blood-brain barrier. Novartis Found Symp 2002, 243:38-47.

34. Dombrowski S, Desai S, Marroni M, Cucullo L, Bingaman W, Mayberg $M R$, Bengez L, Janigro $D$ : Overexpression of multiple drug resistance genes in endothelial cells from patients with refractory epilepsy. Epilepsia 200 I, 42: I504-I507.

35. Potschka $\mathrm{H}$, Fedrowitz $\mathrm{M}$, Loscher $\mathrm{W}$ : Multidrug resistance protein MRP2 contributes to blood-brain barrier function and restricts antiepileptic drug activity. J Pharmacol Exp Ther 2003, 306: |24-|3|.

36. Awasthi S, Sharma R, Yang Y, Singhal SS, Pikula S, Bandorowicz-Pikula J, Singh SV, Zimniak P, Awasthi YC: Transport functions and physiological significance of $\mathbf{7 6} \mathbf{~ k D a}$ Ral-binding GTPase activating protein (RLIP76). Acta Biochim Pol 2002, 49:855-867.

37. Awasthi YC, Sharma R, Cheng JZ, Yang Y, Sharma A, Singhal SS, Awasthi S: Role of 4-hydroxynonenal in stress-mediated apoptosis signaling. Mol Aspects Med 2003, 24:219-230.

38. Yadav S, Zajac E, Singhal SS, Singhal J, Drake K, Awasthi YC, Awasth $S$ : POBI over-expression inhibits RLIP76-mediated transport of glutathione-conjugates, drugs and promotes apoptosis. Biochem Biophys Res Commun 2005, 328:1003-1009.

39. Awasthi S, Cheng J, Singhal SS, Saini MK, Pandya U, Pikula S, Bandorowicz-Pikula J, Singh SV, Zimniak P, Awasthi YC: Novel function of human RLIP76: ATP-dependent transport of glutathione conjugates and doxorubicin. Biochemistry 2000, 39:9327-9334.

40. Singhal SS, Singhal J, Cheng J, Pikula S, Sharma R, Zimniak P, Awasthi YC, Awasthi S: Purification and functional reconstitution of intact ral-binding Gtpase activating protein, RLIP76, in artificial liposomes. Acta Biochim Pol 200I, 48:55I-562.

41. Awasthi S, Singhal SS, Yadav S, Singhal J, Drake K, Nadkar A, Zajac E, Wickramarachchi D, Rowe N, Yacoub A, Boor P, Dwivedi S, Dent P, Jarman WE, John B, Awasthi YC: RLIP76 is a major determinant of radiation sensitivity. Cancer Res 2005, 65:6022-6028.

42. Boonyapisit K, Najm I, Klem G, Ying Z, Burrier C, LaPresto E, Nair D, Bingaman W, Prayson R, Luders H: Epileptogenicity of focal malformations due to abnormal cortical development: direct electrocorticographic-histopathologic correlations. Epilepsia 2003, 44:69-76.

43. Marusic P, Najm IM, Ying Z, Prayson R, Rona S, Nair D, Hadar E, Kotagal P, Bej MD, Wyllie E, Bingaman W, Luders H: Focal cortical dysplasias in eloquent cortex: functional characteristics and correlation with MRI and histopathologic changes. Epilepsia 2002, 43:27-32
Publish with Bio Med Central and every scientist can read your work free of charge

"BioMed Central will be the most significant development for disseminating the results of biomedical research in our lifetime. "

Sir Paul Nurse, Cancer Research UK

Your research papers will be:

- available free of charge to the entire biomedical community

- peer reviewed and published immediately upon acceptance

- cited in PubMed and archived on PubMed Central

- yours - you keep the copyright 